\title{
The Influence of Tehnological Factors on the Yield of Direclty Sown Onion Crop in Mihai Viteazu Area, Cluj County
}

\author{
Felicia Susana BUTUZA BUMB*, Emil LUCA, Enikő LACZI, Păunița BOANCĂ \\ University of Agricultural Sciences and Veterinary Medicine Cluj-Napoca, \\ Department IV Land Measurement and Exact Sciences, Mănăştur Street, No. 3-5, 400372, Romania \\ *)Corresponding author, e-mail: drd.bumb.felicia.1@gmail.com
}

BulletinUASVM Horticulture 72(2) / 2015

Print ISSN 1843-5254, Electronic ISSN 1843-5394

DOI:10.15835/buasvmcn-hort:11311

\begin{abstract}
Onion is one of the most profitable vegetable species, if all technological inputs within a modern technology (from the establishment of the culture to harvest) are taken into consideration. The experiment was located in Mihai Viteazu, Cluj County. In the experiment there were taken into consideration four varieties of onion: 'Roșie de Arieș,, 'Brunswick', 'Density' and 'Sttutgard'. The onion it was sown directly in the field. There were analyzed: the influence of technological factors on the average weight of onion bulb and the influence of on the number of onion bulbs. The three factors in the study (irrigation, fertilization and biological material) differently influenced the onion production per unit of area. In all the experimental variants, the differences between the yeld obtained for the 'Stuttgard' and 'Brunswick' cultivars and the 'Roșie de Arieș' cultivar (control) are very significantly negative, and the yields of the 'Density' cultivar is insignificantly in comparison with the yield of the control cultivar.
\end{abstract}

Keywords: Allium cepa, biological material, fertilization, irrigation.

\section{Introduction}

The onion has been cultivated for 4700 years or more and does not exist as a wild species (Brewster, 2008). Because of the simple methods of cultivation and the high adaptation capacity, the onion was spread in various environmental conditions (Indrea et al., 2012; Popandron, 2012). When the drip irrigation is applied to the onion, the water is gradually distributed in the plant roots and the costs of production are reduced (Luca et al., 2013).

\section{Aims}

The aim of this research was to analyze the influence of several technological factors such as irrigation, fertilization, and cultivar on the yield of directly sown onion.

\section{Material and method}

The experimental protocol group was located in the south of the Mihai Viteazu village, Cluj county, on a terrace reddish brown soil, leachate with $\mathrm{pH}$ between 6.5 and 7.6 units. The research took under study three experimental factors: A factor (irrigation) with $\mathrm{a}_{1}$ non-irrigated and $\mathrm{a}_{2}$ irrigated 70\% IUA graduations; $B$ factor (fertilization) with $b_{1}$ basic fertilization, $b_{2}$ organic fertilization, $b_{3}$ basic and foliar fertilization graduations; $\mathrm{C}$ factor (cultivar) with $\mathrm{c}_{1}$ Roșie de Arieș, $\mathrm{c}_{2}$ Brunswick, $c_{3}$ Density, $c_{4}$ Stuttgart graduations. The onion culture was established by direct sowing in the field. The combination of factors resulted in 24 variants. Was used: the drip irrigation, for the basic fertilization: Complex III, for the organic fertilization fresh:manure dilution, and for the additional foliar fertilization: Ferticare II. For the statistical interpretation it was used the analysis of variance.

\section{Results and discussions}

The interaction of the three factors (irrigation, fertilization and biological material) on the onion 


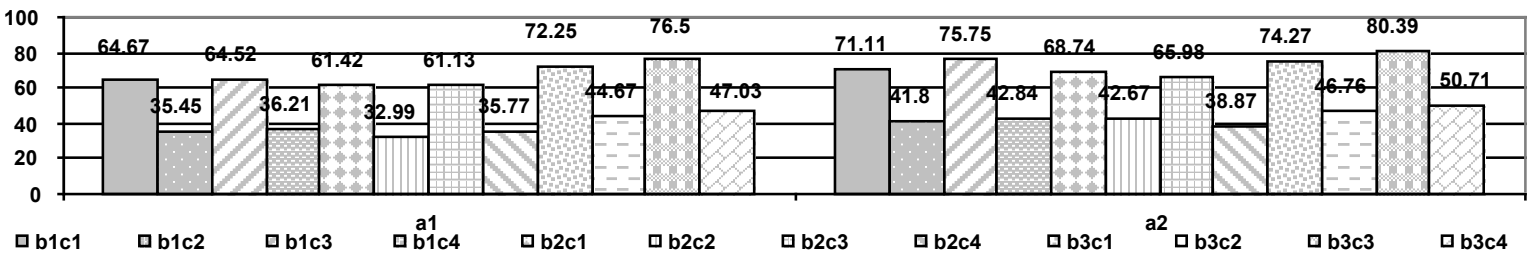

Fig. 1. The influence of the interaction of irrigation with fertilization and cultivar on the onion yield, in 2014, in the Mihai Viteazu area, Cluj county ( $a_{1}=$ non-irrigated; $a_{2}=$ irrigated; $b_{1}=$ basic fertilization; $b_{2}=$ organic fertilization; $b_{3}=$ basic and foliar fertilization; $c_{1}=$ Roșie de Arieș; $c_{2}=$ Brunswick; $c_{3}=$ Density; $c_{4}=$ Stuttgard).

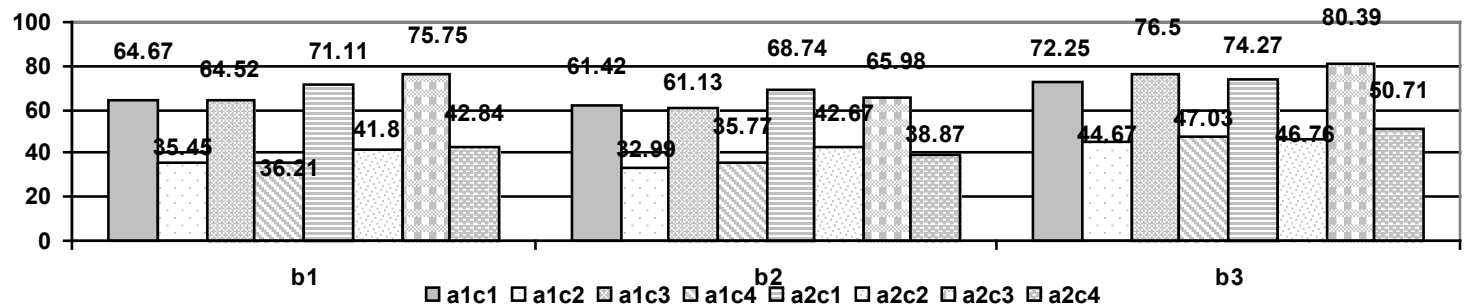

Fig. 2. The influence of the interaction of fertilization with irrigation and cultivar on the onion yield, in 2014 in the Mihai Viteazu area, Cluj county $\left(b_{1}=\right.$ basic fertilization; $b_{2}=$ organic fertilization; $b_{3}=$ basic and foliar fertilization; $\mathrm{a}_{1}=$ non-irrigated; $\mathrm{a}_{2}=$ irrigated; $\mathrm{c}_{1}=$ Roșie de Arieș; $\mathrm{c}_{2}=$ Brunswick; $\mathrm{c}_{3}=$ Density; $\mathrm{c}_{4}=$ Stuttgard).

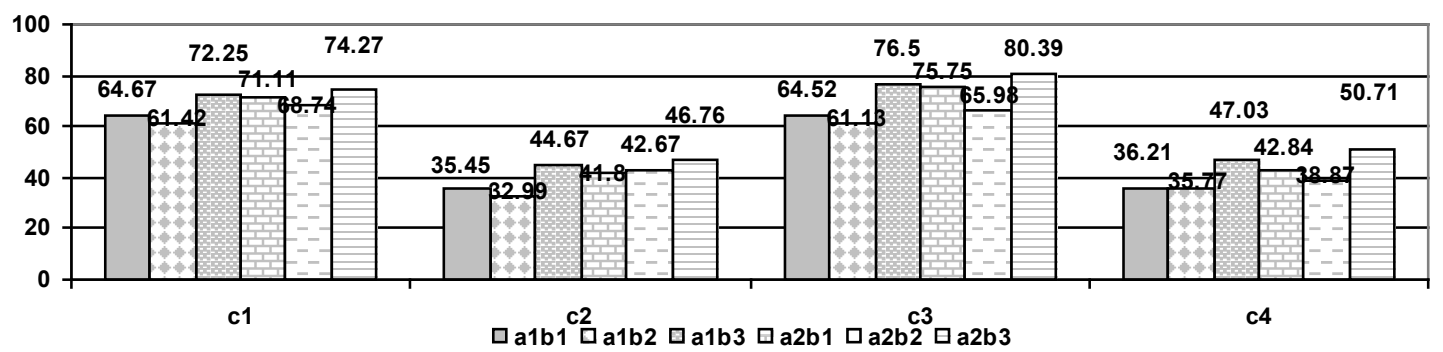

Fig. 3. The influence of the interaction of cultivar with irrigation and fertilization on the onion yield, in 2014, in the Mihai Viteazu area, Cluj county $\left(c_{1}=\right.$ Roşie de Arieş; $c_{2}=$ Brunswick; $c_{3}=$ Density; $c_{4}=$ Stuttgard; $a_{1}=$ nonirrigated; $a_{2}=$ irrigated; $b_{1}=$ basic fertilization; $b_{2}=$ organic fertilization; $b_{3}=$ basic and foliar fertilization).

crop in 2014, shows that the highest yield (80.39 $t / h a)$ was obtained for the variant $a_{2} b_{3} c_{3}$-Density, irrigated, basic and foliar fertilized and the lowest yield (32.99 t/ha) was obtained for the variant $a_{1} b_{2} c_{2}$-Brunswick, non-irrigated, organic fertilized. The irrigated and basic fertilized variant of the Density cultivar reveales a significantly distinct increase of the yield, in comparison with the nonirrigated and basic fertilized variant (control) of the same cultivar, while the irrigated variant of the Brunswick cultivar presents a significantly increase of the yield in comparison with the nonirrigated and organic fertilized variant of the same cultivar. In all the other variants, the yield differences are insignificantly (Fig. 1). In the organic fertilized variant, there is a significantly lower yield of the Density cultivar in the irrigated variant in comparison with the basic fertilized and irrigated variant of the same cultivar (control). The yield differences among the organic fertilized variants and the basic fertilized variants are insignificantly in all the other variants. The yields obtained for the basic and foliar fertilized variants, in comparison with the yields of the basic fertilized variants, are significantly distinct positive for the Density and Stuttgart cultivars in the nonirrigated variants, significantly for Roșie de Arieș, Brunswick and Stuttgart cultivars in the irrigated variants and insignificantly for all the other variants (Fig. 2). In all the experimental variants, the differences between the yield obtained for the Stuttgard and Brunswick cultivars and the Roșie 
de Arieș cultivar (control) are very significantly negative, and the yields of the Density cultivar is insignificantly in comparison with the yield of the control cultivar (Fig. 3)

\section{Conclusions}

Under the conditions of the experimental field $\left(482.4 \mathrm{~m}^{2}\right)$ the cumulated yield of the four varieties was $55.52 \mathrm{t} / \mathrm{ha}$, the varieties Brunswick and Sttutgard having the smallest contribution, with the the lowest average production in comparison with the varieties Roșie de Arieș and Density.

\section{REFERENCES}

1. Brewster JL (2008). Onions and Other Vegetable Alliums 2nd edition. Cab International, Cambridge.

2. Indrea D, Apahidean AS, Apahidean M, Măniutiu D, Sima $\mathrm{R}(2012)$. Vegetable crops. Ed.Ceres, Bucharest.

3. Luca E, Budiu V, Ciotlaus A, Hoble A (2013). Exploitation of land improvement systems. Ed.Risoprint, Cluj-Napoca.

4. 4. Popandron $N$ (2012). Modern technologies for obtaining the onion crops. Ed. Printech Publishing, Bucharest. 